\title{
Facing not-so-natural disasters
}

\author{
Gabriela Litre, Patrícia Mesquita, Marcel Bursztyn e Carlos Hiroo Saito
}

doi:10.18472/SustDeb.v12n2.2021.39361

Climatology is one of the most advanced scientific areas in recent decades. The confluence of factors related to scientific and technological evolution can explain it. Satellite technology has allowed a remarkable increase in data availability and accuracy. Besides, computer science has made possible the evolution of increasingly complex, consistent and capable of treating large databases models, both qualitatively and quantitatively. The results have been more reliable day after day, permitting scenarios' reproduction and discovering trends for more informed decision making. Proof of this advance is a recent article written by Tellman et al., (2021). The manuscript presents available data from flooded areas between 2000-2018 (with a resolution of $250 \mathrm{~m}$ ), identifying an affected area of 2.23 million $\mathrm{km} 2$ and 255 to 290 million people directly impacted by these events worldwide. It represents an increase of 58 to 86 million people between 2000 and 2015, number ten times higher than estimated by other studies. The Global Flood Database ${ }^{1}$ created by these researchers should help identify, among several impacts, the most vulnerable areas and those with a greater need for adaptative measures, especially concerning climate change.

Despite these remarkable advances, recognized/famous climate scientists admit that it has not been possible to predict all recent extreme events, even in countries with a political and scientific commitment to preserving the environment and the fight against climate change, such as Germany. Even with science giving several warnings over decades that rapid global warming would bring worse episodes of rain and more intense heat waves, the tools we have are still not powerful enough to accurately project the level of gravity, the exact moment and the location of the manifestation of these extremes.

Nevertheless, models that point out disasters with accuracy are not enough to prevent them. It is essential to implement planning policies, comply with recommendations and invest in disaster prevention, besides relocating people and facilities outside risk areas.

Some recent examples of extremes events in the world are the floods in Europe and China, forest fires in the United States, Greece and Turkey, extreme heatwaves in Canada or even Siberia, water deficit in Brazil, including a new energy crisis in the middle of the Covid-19 pandemic, extreme weather events in Australia and Africa. Although impacts of climate change occur to a greater extent in the most socioeconomically vulnerable regions, events in Germany and Canada demonstrate that climate disasters can be democratic and equally lethal worldwide.

Prevention costs would be smaller than not investing in it and believing disasters will not occur since this may cause losses with a much higher economic value of remediation. Affected people from these regions make it clear that disasters in smaller magnitudes have already occurred. However, the authorities did not pay due attention. The iteration of these events with an increase in their extent expresses the lack of political decision-making.

Confronting these natural(ish) disasters requires computers for forecasting weather and climate change. Computer science supports the development of climate science. Even if the costs are high for better and larger computers and research support, they are negligible compared to material, economic and human losses associated with extreme events our societies are not ready to face. 
Research still needs to evolve to predict the locations, moments, intensity and cyclical recurrence of countries facing extreme events such as heatwaves or floods. Thus, more sophisticated data and models are needed.

Investing in new computers and research that fills information gaps is not the only answer. There is a lack of action, not only politics! There is a need for collective and creative intelligence adapted to the generation of real-time solutions. Networks of inter- and transdisciplinary researchers (with one foot in academia and the other in the social, private or governmental spheres) should continue to generate knowledge that inspires actions and transformations through collaboration between institutions from different countries. The experience of the United Nations Intergovernmental Panel on Climate Change (IPCC), created in 1988, is an eloquent example of a new modus operandi of the interface of research with public policies. The IPCC has been producing regular reports with analyses, prognoses and recommendations underpinning vital scientific works. It brings together hundreds of researchers and guides government decisions to alert and prevent climate risk and serves as an institutional model for creating similar structures at national scales.

Since it depends on the science timing and a complex web of negotiations to reach consensus among the members of the United Nations, the publication of the IPCC reports every six years - and especially their recommendations to decision-makers - cannot keep up with the frequency to which extreme events occur.

However, one thing is sure: the IPCC reports can point out with very high accuracy that the anthropogenic climate change process has not only accelerated, but it also reached worrying levels in terms of impacts, with significant consequences in the medium and long term(IPCC, 2021). We are talking about fundamental knowledge such as alerts and subsidies to political action of mitigation and adaptation. The latest report, the AR6, warns that the increase in global surface temperatures observed in the last 50 years has been higher than in all other periods for the past 2000 years, with the past 5 being the warmest years since 1850 (IPCC, 2021). Besides, it warns that extreme events' occurrence may increase as never before, even if the global surface temperature increase of $1.5^{\circ} \mathrm{C}$ is maintained.

Some necessary advances may be creating more knowledge, increasing the speed of data generation, collaboration, overcoming impasses due to denialist conducts and seeking convergences. However, this is not enough if, despite the warnings, business-as-usual attitudes continue irresponsible and evasive. Decision-makers procrastination facing adaptative measures and mitigation investments is due to a short-term vision and belief that disasters are unlikely to occur, especially during their political tenure. Even if some maintain rhetoric in line with climate risk alerts, they continue to act opportunistically by choosing to allocate investments in works with greater immediate visibility or postponing regulatory measures that inhibit emission-intensive or degrading activities of ecosystems and their valuable environmental services. They expose a large population and the economy to risk. The intensity and frequency to which material, environmental, human lives are damaged show it makes no sense to continue betting on luck. Disasters are already part of everyday life and force us to think collectively, looking for convergences, and thinking outside the box (and with no prejudices). It is more explicit, day after day, that the costs of adaptation and mitigation are much lower than the damage caused by climate disasters.

In addition to the many lessons that the Covid-19 pandemic gave, the 2021 climate disasters also need to be a lesson. The reduction of inertia and the easing of the gap between knowing there is imminent risk and acting to prevent environmental and human disasters are urgent. As this year confirmed, this can also happen at home, without distinction between more or less developed countries.

Thus, we are growingly receiving alerts that climate disasters punishing our planet are not just natural phenomena. They can also express nature's reaction to the combination of two types of human conduct: the excess of activities that cause greenhouse gas emissions and the lack of actions for adapting and mitigating the effects of these emissions. 
This issue of SeD features ten articles in the Varia section.

In the first article, Gonçalves et al. analyze the variations in land use and land cover in the Macrometropolis of São Paulo and its implications for water resilience under climate change. The authors identify the most vulnerable municipalities and some possible paths to coordinated local and regional actions. Martin and Martins then present an analysis of the potential of photovoltaic generation and supply in the state of São Paulo and its possible implications regarding the sustainability and independence of a centralized generation. Kilian, Triches and Ruiz focus on sustainability and the water footprint analysis of food available in university restaurants, indicating the need for a review of menus and a better dialogue with consumers on the topic of food and sustainability. Finally, in this block, Carvalho, Iwama and La Rovere present scenarios for oil palm expansion in degraded and deforested areas of the Brazilian Amazon for biodiesel demand. They highlight the need for public policies aimed at the recovery of these areas for palm oil cultivation.

From a historical perspective, Ribeiro and Vieira discuss the trajectory and resilience of an agroextractive settlement project in Pará. They point out that the transition from sugarcane to açaí allowed riparians to experience changes and create conditions to reorganize in settlements. Prioste, Formiga-Johnsson and Ohnuma Júnior present a content analysis around the historical influence of ancient societies' ideas regarding sustainable water management in Rio de Janeiro. They observe that society replicates some models of sustainable management. Bertuluci, Ferreira, and Silva Júnior debate the Anthropocene idea and indicate how the different approaches mobilized by the Anthropocene central issue imply theoretical movements of redefinition of the relations between agency, structure and social change in the historical context of modern industrial societies.

Finally, Ortiz-Paniagua, Valencia and Esparza analyze the University Social Responsibility policy of a Mexican university. They offer a model that helps to identify focus areas and sectors for better performance. Perez-Castillo presents an impact assessment methodology based on benefit indicators for agroecological producer markets also tested in Mexico. And lastly, Matte et al. discuss the potential of dialogue networks as tools for rural women recognition and overcoming their traditional marginalization in the field. They present recommendations on the need for actions and policies that provide environments that reframe women role in society and families.

Enjoy your reading!

\section{NOTES}

Available in: https://global-flood-database.cloudtostreet.ai. Acessed: 6 Aug 2021.

\section{REFERENCES}

THE INTERGOVERNMENTAL PANEL ON CLIMATE CHANGE. Summary for Policymakers. In: MASSON-DELMOTTE, V. et al. (Ed.). Climate Change 2021: the physical science basis. Contribution of Working Group I to the Sixth Assessment Report of the Intergovernmental Panel on Climate Change Cambridge University Press. In Press, 2021.

TELLMAN, B. et al. Satellite imaging reveals increased proportion of population exposed to floods. Nature, v. 596, p. 80-86, 2021. Available in: https://doi.org/10.1038/s41586-021-03695-w. Acessed: 5 Aug 2021. 